\title{
The Strategic Advantage of Inequality Averse Preferences
}

\author{
Özgür Yılmaz* \\ Koç University
}

\begin{abstract}
It is usually assumed that the sole purpose of agents is to maximize their own material payoff independently from what other agents receive, and that this yields a strategic advantage in terms of receiving a higher payoff compared to other types of players, if any. On the contrary, it is shown that in certain subclasses of games, players with negatively interdependent preferences have an unambiguous strategic advantage over the independent players (Koçkesen et al., 2000). We analyze a different type of interdependency in games; in particular, we analyze games where players with inequality averse preferences have a strategic advantage over the independent players.
\end{abstract}

Keywords: strategic advantage, supermodular games, inequality averse preferences.

Journal of Economic Literature Classification Numbers: C72, D62.

\section{Eşitsizlik Karşıtı Tercihlerin Stratejik Avantajı}

\section{Özet}

Genel olarak, bireylerin iktisadi kararlar alırken, kendi çıkarlarının azami olmasını sağlamaktan başka bir hedeflerinin olmadığı, herhangi bir paylaşımdan aldıkları faydanın da diğer bireylerin elde ettiklerinden bağımsız olduğu ve bu motivasyonun stratejik bir avantaj sağladığı varsayılır. Fakat gösterilmiştir ki, bazı oyun kümelerinde, diğer bireylerin elde ettikleri ile negatif bir bağımlılık içeren tercihler stratejik bir avantaj sağlamaktadır (Koçkesen v.d., 2000). Bu çalışmada, başka türlü bir bağımlılık içeren tercihleri, eşitsizlik karşıtı tercihleri, stratejik avantaj açısından inceliyoruz.

Anahtar kelimeler: stratejik avantaj, süpermoduler oyunlar, eşitsizlik karşıtı tercihler.

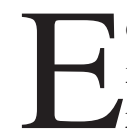

conomic theory usually adopts the assumption that individual preferences are independent and that the agents' sole purpose is to maximize their own material payoff. This assumption is based (at least partially) on the belief that this behavioral motive brings a higher payoff in strategic situations. This view is challenged by several authors (e.g. Vickers, 1984; Fershtman and Judd, 1987; and Koçkesen et al., 2000). On the other hand, there is a growing literature on the weakness of the assumption

Özgür Yılmaz is an Assistant Professor in the Department of Economics at Koç University, Rumelifeneri Yolu, 34450, Sarıyer, Istanbul, Turkey. E-mail: oyilmaz@ku.edu.tr 
that all agents are self-interested. There are many works arguing that agents not only care about their own material payoff and well-being but also have other motives like fairness towards an egalitarian distribution of the resources. Given these two lines of research, we ask the following question: Are there classes of strategic encounters where agents with fairness motives have a strategic advantage (in the sense of receiving a higher payoff) over the self-interested agents? Our result shows the existence of such cases.

Payoff maximization is widely considered to be a realistic assumption in strategic situations because of the impression that self-interested agents receive higher payoffs than the other types of agents. This is challenged in a model where there are some agents with independent, payoff maximizing preferences and some agents with interdependent preferences: It is shown that under certain classes of games, at all intragroup symmetric Nash equilibria, agents with interdependent preferences have an unambiguous strategic advantage over the agents with independent, self-interested preferences; that is, each agent of the former type receives a higher material payoff than each agent of the latter type. (Koçkesen et al., 2000). Here, interdependence is assumed to be negative, that is, an agent with interdependent preferences not only cares about her own material payoff but also about her payoff relative to others.

While this model of negatively interdependent preferences provides us with a valuable insight, there are other types of interdependent preferences. Recent experiments have uncovered that in some (but not all) situations people do not only pursue their own material self-interest, but they also care about others well-being. ${ }^{([1])}$ Inequality aversion is an example of that kind of altruism. We adopt such a model of preferences following Fehr and Schmidt (1999) and assume that there are agents who dislike inequitable outcomes: These agents dislike not only the inequality if they are worse off in material terms than the other players but also the inequality if they are better off; moreover, in general, they dislike inequality that is to their material disadvantage a bit less than they dislike inequality that is to their material advantage.

We analyze games where agents with inequality averse preferences have a strategic advantage over agents with independent preferences. By imposing certain conditions on the structure of the normal form game, we show that there are classes of games where inequality averse preferences have an unambiguous strategic advantage over independent players; that is, they receive a higher payoff than independent players.

\section{The Model}

Let $N=\{1, \ldots, n\}$ be the set of players. Let $X$ be the action space and $\pi_{r}: X^{n} \longrightarrow \mathbb{R}$ the absolute payoff function of player $r$. Since our goal is to compare material payoffs obtained by different preference structures, in order to exclude any type of a priori

[1] This vast literature on these type of experiments includes ultimatum bargaining, dictatorship games and public goods games, among others. The main point of the analysis is the exploration of behavior and the degree that it deviates from the classical assumption of self-interested and payoff maximizing individuals. See for example, Andreoni and Miller (1996), Blount (1995), Bolton (1991), Bolton and Ockenfels (2000), Guth and Tietz (1990), Ledyard (1995), Levine (1998), Ochs and Roth (1989), Prasnikar and Roth (1992), Rabin (1993), and Roth et al. (1991). 
advantage in terms of the primitives of the game by some players, the focus is on symmetric games. Thus, $\pi_{r}(x)=\pi_{q}\left(x^{\prime}\right)$ for all $r, q=1, \ldots, n$ and all $x, x^{\prime} \in X^{n}$ such that $x^{\prime}$ is obtained from $x$ by exchanging $x_{r}$ and $x_{q}$. Using $\Gamma$ we denote a symmetric $n$-game in normal form. That is,

$$
\Gamma \equiv\left(X,\left\{\pi_{r}\right\}_{r=1, \ldots, n}\right)
$$

We assume that $\Gamma$ satisfies the following non-negativity conditions:

$$
\pi_{r}(x) \geqslant 0 \quad \forall x \in X^{n} \quad \text { and } r=1, \ldots, n \text {. }
$$

The class of all $\Gamma$ that satisfy these assumptions is denoted by $\mathcal{G}$. We denote the set of all Nash equilibria of $\Gamma \in \mathcal{G}$ by $N(\Gamma)$.

The set of players consists of independent and interdependent types. The independent players maximize their absolute payoffs. The objective function of an independent player is precisely her own material payoff function. On the other hand, interdependent players are concerned not only with their absolute payoffs, but also with the inequality of the players in terms of absolute payoffs. These players dislike inequitable outcomes. structurally For the normal formal game we adopt the utility representation suggested by Fehr and Schmidt (1999). The objective function of an interdependent player is the following:

$$
\begin{aligned}
U_{i}(\pi)= & \pi_{i}-\alpha_{i} \frac{1}{n-1} \sum_{j \neq i} \operatorname{Max}\left\{\pi_{j}-\pi_{i}, 0\right\} \\
& -\beta_{i} \frac{1}{n-1} \sum_{j \neq i} \operatorname{Max}\left\{\pi_{i}-\pi_{j}, 0\right\}
\end{aligned}
$$

where $\alpha_{i} \geqslant \beta_{i}$. For analytical tractability, we take $\alpha_{i}=\beta_{i}$. Then, utility representation of the inequality averse preferences is reduced to the following:

$$
U_{i}(\pi)=\pi_{i}-\alpha_{i} \frac{1}{n-1} \sum_{j \neq i}\left|\pi_{j}-\pi_{i}\right|
$$

Inequality aversion is suggested as a concept to capture the fairness consideration of interdependent players. Inequality averse preferences are not monotonic in general. An inequality averse player may prefer a lesser amount of material payoff to avoid large inequalities.

\section{Main Result}

Our goal is to analyze certain classes of symmetric games in which inequality averse players get higher material payoffs compared to the independent players' payoffs. First, we give a simple example to illustrate this possibility. Below is a $2 \times 2$ normal formal game which is not symmetric: 


\begin{tabular}{|c|c|c|}
\hline $1 \backslash 2$ & $l$ & $r$ \\
\hline$u$ & 20,50 & 30,40 \\
\hline$d$ & 50,10 & 0,0 \\
\hline
\end{tabular}

If we assume standard preferences, the second player has a dominant strategy, $l$, and $(d, l)$ is the unique equilibrium, where $50=\pi_{1}>\pi_{2}=10$. Now, suppose that the first player is independent and the second player has inequality averse preferences with $\alpha_{2}=0.8$. The normal form game under these preferences/utilities is represented by the following:

\begin{tabular}{|c|c|c|}
\hline $1 \backslash 2$ & $l$ & $r$ \\
\hline$u$ & 20,26 & 30,32 \\
\hline$d$ & $50,-22$ & 0,0 \\
\hline
\end{tabular}

Given that the preferences are common knowledge, the unique equilibrium of this game is $(u, r)$. Note that $30=\pi_{1}<\pi_{2}=40$.

Although asymmetry is crucial in this example and we will concentrate on symmetric games, it makes our intention explicit: Are there games (or classes of games) in which players with inequality averse preferences have a strategic advantage over independent players, i.e. in which these players' material payoffs are higher than the independent players' material payoffs?

Suppose that exactly $k \in\{1, \ldots, n-1\}$ players in $\Gamma \in \mathcal{G}$ are independent and $n-k$ players have inequality averse preferences. We denote the set of independent players by $I_{k}=\{1, \ldots, k\}$ and the set players with inequality averse preferences by $J_{k}=\{k+1, \ldots, n\}$. We define the $n$-person normal form game

$$
\Gamma_{U}(k) \equiv\left(X,\left\{p_{r}\right\}_{r=1, \ldots, n}\right)
$$

with the utilities $\left\{p_{r}\right\}_{r=1, \ldots, n}$ defined as

$$
p_{r}(\pi) \equiv \begin{cases}\pi_{r} & \text { if } r \in I_{k} \\ U_{r}(\pi) & \text { if } r \in J_{k}\end{cases}
$$

We assume that the players' types and their preferences are common knowledge among the players, and therefore they are engaged in playing $\Gamma_{U}(k)$. The main difficulty in analyzing the pure strategy Nash equilibria of this game is the analytical tractability of certain asymmetric equilibria. The analysis is greatly simplified (as in Koçkesen et al., 2000) when we restrict our analysis to the intragroup symmetric Nash equilibria, 
denoted by $N_{\text {sym }}\left(\Gamma_{U}(k)\right)$ and defined as

$$
N_{s y m}\left(\Gamma_{U}(k)\right) \equiv\left\{\left([a]_{k},[b]_{n-k}\right) \in N\left(\Gamma_{U}(k)\right): a, b \in X\right\}
$$

where $[t]_{l}$ denotes the $l$ - replication of the object $t$.

The example above is about the comparison of material payoffs of different types of players. We need to formalize this idea.To be specific, we are interested in identifying some general subclasses of $\mathcal{G}$ where the interdependent players have a strategic advantage over the independent players in terms of monetary payoffs. That is,

$$
\pi_{j}(\widehat{x})>\pi_{i}(\widehat{x}) \quad \forall(i, j) \in I_{k} \times J_{k} \quad \text { and } \quad \widehat{x} \in N_{\text {sym }}\left(\Gamma_{U}(k)\right) .
$$

\section{Supermodular Games}

We endow the action space with a relation. Let $\succsim$ be a linear order on $X$. The set $X^{n}$ is a lattice if for each pair $x$ and $y$, the lowest upper bound of $x$ and $y(x \vee y)$ and the greatest lower bound of $x$ and $y(x \wedge y)$; both with respect to the product order induced by $\succsim$, are in $X^{n}$. An $n$-person normal form game $\Gamma \in \mathcal{G}$ is said to be supermodular whenever

$$
\pi_{r}(x \vee y)+\pi_{r}(x \wedge y) \geqslant \pi_{r}(x)+\pi_{r}(y) \quad \forall x, y \in X^{n} \quad \text { and } \quad r=1, \ldots, n,
$$

A game $\Gamma$ is strictly supermodular if the above inequality holds strictly for all $r$ and $x, y \in X^{n}$ such that $\{x \vee y, x \wedge y\} \neq\{x, y\}$. Supermodular games are such that each player's marginal utility of increasing her strategy rises with increases in his rival's strategies. In such games the best response correspondences are increasing, so that the players' strategies are 'strategic complements' (Bulow et al., 1985; Topkis, 1979; Vives, 1990; Koçkesen et al., 2000). We next define games with action monotonicity and spillovers.

Definition: (Action Monotonicity) An $n$ - person normal form game $\Gamma \in \mathcal{G}$ is said to be positively (negatively) action monotonic if for all $x \in X^{n}, x_{r} \succ(\prec) x_{q}$ implies $\pi_{r}(x)>\pi_{q}(x)$.

While action monotonicity is not a standard property, it is satisfied by a variety of well-known games. ${ }^{[2]}$

Definition: (Spillovers) Let $\mathcal{A} \equiv \bigcup_{k=1}^{n-1}\left\{x \in N_{\text {sym }}\left(\Gamma_{U}(k)\right)\right\}$.

An $n$ - person normal form game $\Gamma \in \mathcal{G}$ is said to have negative spillovers, if for any $x \in \mathcal{A}$,

$t^{1} \succ x_{r} \succ t^{2} \quad$ implies $\quad \pi_{q}\left(x_{-r}, t^{1}\right)>\pi_{q}(x)>\pi_{q}\left(x_{-r}, t^{2}\right)$

for all $r$ and $q \neq r$.

${ }^{[2]}$ See Koçkesen et al., 2000 for a discussion on this property. 
Definition: (Increasing Spillovers) Let $\mathcal{A} \equiv \bigcup_{k=1}^{n-1}\left\{x \in N_{\text {sym }}\left(\Gamma_{U}(k)\right)\right\}$.

An $n$ - person normal form game $\Gamma \in \mathcal{G}$ is said to have increasing spillovers if for any $x \in \mathcal{A}$ such that $x_{i} \succ x_{j}$,

$$
\begin{aligned}
t^{1} & \succ x_{r} \succ t^{2} \text { implies } \\
\pi_{i}\left(x_{-r}, t^{1}\right)-\pi_{i}(x) & >\pi_{j}\left(x_{-r}, t^{1}\right)-\pi_{j}(x)
\end{aligned}
$$

and $\pi_{i}\left(x_{-r}, t^{2}\right)-\pi_{i}(x)<\pi_{j}\left(x_{-r}, t^{2}\right)-\pi_{j}(x)$

for all $r \notin\{i, j\}$. Games with decreasing spillovers are defined dually.

Theorem: Let $k \in\{1, \ldots, n-1\}$. Assume that interdependent players are in a weak minority:

$n-k \leq k$

(Minority condition)

If $\Gamma \in \mathcal{G}$ is strictly supermodular, is positively action monotonic and has negative and decreasing spillovers, then for any $\widehat{x} \in N_{\text {sym }}\left(\Gamma_{U}(k)\right)$ with $\pi_{j}(\widehat{x}) \neq \pi_{i}(\widehat{x})$, we have $\pi_{j}(\widehat{x})>\pi_{i}(\widehat{x})$ for all $(i, j) \in I_{k} \times J_{k}$.

Proof: Take any $\widehat{x}=\left([a]_{k},[b]_{n-k}\right) \in N_{\text {sym }}\left(\Gamma_{U}(k)\right)$ with $a \neq b$. Since $p_{1}(\widehat{x})=\pi_{1}(\widehat{x})$ and $\widehat{x}$ is an equilibrium, wehave $\pi_{1}\left([a]_{k},[b]_{n-k}\right) \geqslant \pi_{1}\left(b,[a]_{k-1},[b]_{n-k}\right)$ This together with symmetry of $\Gamma$ yields

$$
\pi_{n}\left(b,[a]_{k-1},[b]_{n-k-1}, a\right) \geqslant \pi_{n}\left(b,[a]_{k-1},[b]_{n-k}\right)
$$

By strict supermodularity, since $a \neq b$ we have

$$
\begin{aligned}
& \pi_{n}\left([a]_{k},[b]_{n-k}\right)+\pi_{n}\left(b,[a]_{k-1},[b]_{n-k-1}, a\right) \\
< & \pi_{n}\left([a]_{k},[b]_{n-k-1}, a\right)+\pi_{n}\left(b,[a]_{k-1},[b]_{n-k}\right)
\end{aligned}
$$

By combining (1) and (2), we obtain

$$
\pi_{n}\left([a]_{k},[b]_{n-k}\right)=\pi_{n}(\widehat{x})<\pi_{n}\left(\widehat{x}_{-n}, a\right) .
$$

If $b \succ a$ then $\pi_{n}(\widehat{x})>\pi_{1}(\widehat{x})$ by action monotonicity and we are done. Suppose that $\widehat{x}_{1}=a \succ b=\widehat{x}_{n}$. But then it must be $\pi_{1}(\widehat{x})>\pi_{n}(\widehat{x})$, by action monotonicity. Player $n$ 's subjective utility in this case is the following:

$$
p_{n}(\widehat{x})=U_{n}(\widehat{x})=\pi_{n}(\widehat{x})-\alpha_{n} \frac{k}{n-1}\left[\pi_{1}(\widehat{x})-\pi_{n}(\widehat{x})\right] .
$$

Note that for player $n$, inequality arises from the differences in material payoffs of herself and the players in $I_{k}$; and there are $k$ such players. Suppose player $n$ deviates from $b$ to $a$. Since the game has negative spillovers, it must be that the material payoff of everyone but player $n$ decreases when such a deviation occurs. Thus, for all $j \in J_{k} \backslash\{n\}$ and for all $i \in I_{k}$ 


$$
\pi_{j}\left(\widehat{x}_{-n}, a\right)<\pi_{n}(\widehat{x})<\pi_{n}\left(\widehat{x}_{-n}, a\right)=\pi_{i}\left(\widehat{x}_{-n}, a\right)<\pi_{i}(\widehat{x}) .
$$

The first and last inequality follow from negative spillovers. The second inequality follows from (3), and the equality is by symmetry. Now, the utility of player $n$ is the following:

$$
p_{n}\left(\widehat{x}_{-n}, a\right)=U_{n}\left(\widehat{x}_{-n}, a\right)=\pi_{n}\left(\widehat{x}_{-n}, a\right)-\alpha_{n} \frac{n-k-1}{n-1}\left[\pi_{n}\left(\widehat{x}_{-n}, a\right)-\pi_{j}\left(\widehat{x}_{-n}, a\right)\right]
$$

where $j \in J_{k} \backslash\{n\}$. Since $\Gamma$ has decreasing spillovers and $\widehat{x}_{1}=a \succ b=\widehat{x}_{n}$, we obtain

$$
\pi_{j}\left(\widehat{x}_{-n}, a\right)-\pi_{n}(\widehat{x})>\pi_{1}\left(\widehat{x}_{-n}, a\right)-\pi_{1}(\widehat{x}) .
$$

By symmetry we can rewrite this inequality as follows:

$$
\pi_{1}(\widehat{x})-\pi_{n}(\widehat{x})>\pi_{n}\left(\widehat{x}_{-n}, a\right)-\pi_{j}\left(\widehat{x}_{-n}, a\right)
$$

which means that the difference between the lowest and highest material payoffs shrinks. This difference is the source of inequality for player $n$, thus she derives a disutility from it. Moreover, for player $n$, there are $n-k-1$ players with a different payoff after the deviation. (Note that at $\widehat{x}$, there are $k$ players with a different payoff than the payoff of player $n$.) With the minority condition, $n-k-1<k$. Thus, the number of such inequalities between player $n$ and the rest of the players decreases. Thus, for player $n$, both the material payoff increases and the disutility from the sum of the inequalities between herself and the rest of the players decreases. Thus, player $n$ is strictly better off, which is a contradiction.

\section{Discussion of Our Result}

Our result demonstrates that there is a class of the games for which players with inequality averse preferences receive a higher payoff than independent players who maximize their own material payoff. The interesting feature of this result is that this class of games is a subclass of supermodular and action monotonic games, for which it is already shown that players with negatively interdependent preferences receive a higher payoff than independent players (Koçkesen et al., 2000). It is interesting because, for a given level of individual payoff, while negatively interdependent type players prefer to receive a higher than the average payoff, inequality averse type players prefer to receive the average payoff. The difference between our result and the main result of Koçkesen et al., 2000 is obviously due to the different assumptions regarding the preferences. First, note that these two results are independent. Second, both results assume supermodularity of the games. Supermodularity, a strategic complementarity property, implies that for a symmetric strategy profile $\widehat{x}=\left([a]_{k},[b]_{n-k}\right)$. If $a$ is a best response to $b$, then it is also a better response to $a$ than $b$, as inequality (3) is shown to hold for supermodular games (see also Koçkesen et al., 2000). The main result of Koçkesen et al., 2000 relies on this inequality and action monotonicity in the following way: If $\widehat{x}=\left([a]_{k},[b]_{n-k}\right)$ is a symmetric strategy profile, where player $n$ (a negatively interdependent type player) 
receives a lower payoff than player 1 (an independent type player), then by simply deviating to strategy $a$, player $n$ can increase not only her payoff (by supermodularity) but also her relative payoff (by action monotonicity). Thus, her utility would increase and it would mean that $\widehat{x}$ cannot be a Nash equilibrium. For the games where interdependent type players have inequality averse preferences, one needs a slightly different argument: Given a strategy profile $\widehat{x}=\left([a]_{k},[b]_{n-k}\right)$, where player $n$ (an inequality averse player) receives a lower payoff than player 1 (an independent type player), first, player $n$ can increase her payoff by deviating to strategy $a$ due to supermodularity (as in Koçkesen et al., 2000). Moreover, negative and decreasing spillovers guarantee that the difference between the two levels of payoffs decrease after this deviation: the first difference being between the payoffs of player $n$ and player 1 , the second difference being between the payoffs of player $n$ and another player $j$ with inequality averse preferences, i.e. $j \in J_{k} \backslash\{n\}$. Also, after deviation, she receives the same payoff with $k$ other agents and a different payoff than $n-k-1$ agents; on the other hand, at $\widehat{x}$, she receives the same payoff with $n-k-1$ other agents and a different payoff than $k$ agents. Thus, inequality from the perspective of agent $n$ decreases by the minority condition, which means by deviating to $a$, she not only increases her material payoff, but also decreases inequality between her payoff and others' payoff. This implies that she is better off by deviating to strategy $a$. Thus, at equilibrium, a player with inequality averse preferences receives a higher payoff than an independent, payoff maximizing player. It is important to note that, at $\widehat{x}$, by deviating to strategy $a$, player $n$ not only decreases the inequality but also receives a payoff above average and increases her relative payoff (this is also implied by the main theorem of Koçkesen et al., 2000 and note that a higher relative payoff can occur along a lower level inequality; these two are not mutually exclusive). Thus, our contribution is to characterize new properties (in addition to supermodularity and action monotonicity) to obtain a strategic advantage in favor of not only negatively interdependent players but also inequality averse players.

\section{Conclusion}

It is already argued that agents with certain types of interdependent preferences may obtain a strategic advantage in some subclasses of games. Koçkesen et al., 2000 show that players with negatively interdependent preferences have a strategic advantage in strictly supermodular and action monotonic games over the set of independent players. We showed that a similar result can be obtained for the players with inequality averse preferences. In particular, we showed that players with inequality averse preferences have a strategic advantage over the independent players in games which are strictly supermodular, are positively action monotonic and have negative and decreasing spillovers. 


\section{References}

Andreoni, J. and Miller, J. (1996). "Giving According to GARP: An Experimental Study of Rationality and Altruism," SSRI Working Paper, University of Wisconsin, Madison.

Blount, S. (1995). “When Social Outcomes Aren't Fair: The Effect of Causal Attributions on Preferences," Organizational Behavior and Human Decision Process, 43: 131-144.

Bolton, G. (1991). “A Comparative Model of Bargaining: Theory and Evidence," American Economic Review, 81(5): 1096-1136.

Bolton, G. and Ockenfels, A. (2000). "ERC: A Theory, of Equity, Reciprocity, and Competition," American Economic Review, 90(1): 166-193.

Bulow, J., Geanakopolos, J., and Klemperer, P. (1985). "Multimarket Oligopoly: Strategic Substitutes and Complements," Journal of Political Economy, 93: 488-511.

Fehr, E. and Schmidt, K. (1999). "A Theory of Fairness, Competition, and Cooperation," Quarterly Journal of Economics, 114: 817-868.

Fershtman, C. and Judd, K.L. (1987). "Incentive Equilibrium in Oligopoly," American Economic Review, 77: 927-940.

Guth, W. and Tietz; R. (1990). "Ultimatum Bargaining Behavior-A Survey and Comparison of Experimental Results," Journal of Economic Psychology, 11: 417-449.

Koçkesen, L., Ok, E., and Sethi, R. (2000). "The Strategic Advantage of Negatively Interdependent Preferences," Journal of Economic Theory, 92: 274-299.

Ledyard, J. (1995). "Public Goods: A Survey of Experimental Research," in J. Kagel and A. Roth (eds.), Handbook of Experimental Economics: 111-194. Princeton: Princeton University Press.

Levine, D. (1998). "Modelling Altruism and Spitefulness in Experiments," Review of Economic Dynamics, 1(3): 593-622.

Ochs, J. and Roth, A. (1989). "An Experimental Study of Sequential Bargaining," American Economic Review, 79: 355-384.

Prasnikar, V. and Roth, A. (1992). "Considerations of Fairness and Strategy: Experimental Data from Sequential Games,” Quarterly Journal of Economics, 107: 865-888.

Rabin, M. (1993). “Incorporating Fairness into Game Theory," American Economic Review, 83(5): 1281-1302.

Roth, A., Prasnikar, V., Okuno-Fujiwara, M., and Zamir, S. (1991). "Bargaining and Market Behavior in Jerusalem, Ljubljana, Pittsburgh, and Tokyo," American Economic Review, 81(5): 1068-1095.

Topkis, D.M. (1979). "Equilibrium Points in Nonzero-sum n-person Submodular Games," SIAM Journal of Continuous Optimization, 17: 773-787.

Vickers, J. (1984). "Delegation and the Theory of the Firm," Economics Journal Supplement, 95: 138-147.

Vives, X. (1990). "Nash Equilibrium with Strategic Complementarities," Journal of Mathematical Economics, 19: 305-321. 